\title{
Landslide Susceptibility Analysis by Type of Cultural Heritage Site Using Ensemble Model: Case Study of the Chungcheong Region of South Korea
}

\author{
Jun Woo Kim ${ }^{1}$ and Ho Gul Kim²* \\ ${ }^{1}$ Graduate School, Department of Environment Landscape Architecture, Cheongju University, \\ Cheongju 28503, Republic of Korea \\ ${ }^{2}$ Major in Landscape Urban Planning, Department of Human Environment Design, Cheongju University, \\ Cheongju 28503, Republic of Korea
}

(Received August 20, 2021; accepted November 11, 2021)

Keywords: spatial distribution model, time series analysis, landslide adaptation measure, priority analysis

The damage caused by landslides is increasing worldwide due to climate change. In Korea, damage from landslides occurs frequently, making it necessary to develop effective response strategies. Presently, the consideration of cultural heritage sites in these strategies is insufficient. The purpose of this study is to analyze the spatial relationship between cultural heritage sites in the Chungcheong region of Korea and some areas susceptible to landslides. The Chungcheong region has many historically important cultural heritage sites. There are various relics in landslide susceptibility areas (LSAs), with sites associated with religion (171), history (148), traditional architecture (138), tombs (92), educational institutions (47), landscapes (20), and irrigation facilities (2). Additionally, the percentages of LSAs with different types of cultural heritage sites were investigated and found to be as follows: landscapes (37.03\%), tombs (27.72\%), religion $(26.06 \%)$, history $(25.32 \%)$, education (25.26\%), traditional buildings $(24.74 \%)$, and irrigation facilities $(18.75 \%)$. According to the judgment process of prioritizing prevention measures, sites associated with history should be given the highest priority to prevent landslide damage, followed by those associated with religion. The approach and results of this study are expected to help prevent landslide damage in cultural heritage sites by aiding the development of decision-making strategies.

\section{Introduction}

The intensity and frequency of torrential rain and typhoons are increasing worldwide due to climate change, and the damage from landslides is increasing. ${ }^{(1)}$ South Korea suffers from frequent landslides and spends hundreds of billions of won each year on preventing them and restoring damaged areas. (2) Landslides cause casualties and property damage as well as direct and indirect damage to roads and major facilities. Thus, assessing the degree of landslide damage should be considered as a serious and important management issue. ${ }^{(3)}$

*Corresponding author: e-mail: khgghk87@gmail.com https://doi.org/10.18494/SAM.2021.3593 
In South Korea, where mountainous areas account for most of the country, cultural heritage sites are often located in mountainous areas, especially those made of stone, which are damaged by natural disasters such as landslides and earthquakes and often have no special protection facilities. $^{(4,5)}$ A total of 432 cultural heritage sites were damaged by natural disasters such as torrential rain and storms from 2008 to 2017, and the budget for the restoration of the damage was 34.2 billion won. ${ }^{(6)}$ The Cultural Heritage Administration spends more than 600 billion won annually on preserving cultural heritage sites and establishing disaster prevention systems, but the extent of damage to cultural heritage sites in 2020 was four times that in 2017. ${ }^{(7)}$ If the incidence of torrential rain and typhoons increases due to climate change, the damage and destruction of cultural heritage sites caused by landslides are expected to increase. Cultural heritage sites are an important asset, serving as a compendium of human history and cultural activities, making it necessary to prevent them from damage caused by landslides.

To prevent landslide damage and casualties, research studies to analyze landslide susceptibility areas (LSAs) and landslide occurrence and establish response strategies are in progress. $^{(8)}$ Identifying and managing LSAs before landslides occur help to minimize the damage caused by landslides. Studies are presently being conducted to develop a new landslide susceptibility (LS) analysis methodology by combining logistic regression analysis, an artificial neural network, and a random forest. ${ }^{(9)}$ Furthermore, studies to evaluate LS using the maximum entropy model, ${ }^{(10-12)}$ GIS-based machine studies to evaluate LS using learning techniques, ${ }^{(1,13)}$ and studies to evaluate landslide risks using machine learning and synthetic aperture radar (SAR) techniques ${ }^{(14)}$ are also being conducted.

Existing research on LSAs has focused on internal damage to forests, or on areas adjacent to forests where landslides cause damage to human lives and infrastructure. ${ }^{(15)}$ Cultural heritage sites are characterized by deterioration of their condition over time, continuous exposure to damage from disasters, and an inability to restore them to their original form after damage. ${ }^{(16)}$ However, there has been insufficient research on the possibility of landslide damage to cultural heritage sites, a valuable asset of humanity. ${ }^{(17,18)}$ In particular, considering that the number of natural disasters has been increasing recently and many domestic cultural heritage sites are located in forests, an urgent task is to evaluate their LS. Therefore, in this study, we investigate the relationship between cultural heritage sites and LSAs in the Chungcheong region, which has a rich cultural history and has been suffering from landslides.

Additionally, most studies have only considered information about landslide sites at a specific time in the process of analyzing LSAs. ${ }^{(19)}$ This is because cases of landslides repeatedly occurring in the same area over many years are rare, and many studies have been conducted only at specific times when weather changes have occurred. However, if the information on landslides at a particular time alone is used to analyze LSAs, the specificity of the results will increase. ${ }^{(20)}$ This limitation can be improved by considering the information of landslide occurrence in multiple years; in this study, we attempt to improve the information on landslide occurrence in four target years in the target region.

The purpose of this study was to analyze LSAs and their spatial relationship with cultural heritage sites in the Chungcheong region to prevent and reduce damage to cultural heritage sites caused by landslides. In particular, the government intends to identify the priority level of sites 
when preventing landslides by classifying, various cultural heritage sites in the Chungcheong region and confirming that many LSAs have different types of cultural heritage sites. The results of this study are expected to help prevent landslide damage to cultural heritage sites by providing decision makers with information on the types and locations of sites that are urgently in need of landslide prevention measures.

\section{Methods}

\subsection{Scope of study}

The spatial scope of this study includes Chungcheongbuk-do, Chungcheongnam-do, Sejong, and Daejeon Metropolitan City (Fig. 1). The Chungcheong region is located in the center of South Korea and is an important historical and cultural area with 1255 cultural heritage sites. The years selected for this study are 2011, 2012, 2017, and 2018, in which landslides occurred frequently in the Chungcheong region.

The research protocol used in this study was as follows. First, to construct environmental variables, prior research on landslides was referenced, and the environmental variables selected were rainfall, topography, and land use, which are considered the main causes of landslides. The information on landslide sites was provided by the Korea Forestry Administration. Information on the location and area of cultural heritage sites designated by the government was established on the basis of the coordinates of cultural heritage sites provided by the Cultural Heritage Administration. The environmental variables were entered into the spatial distribution model

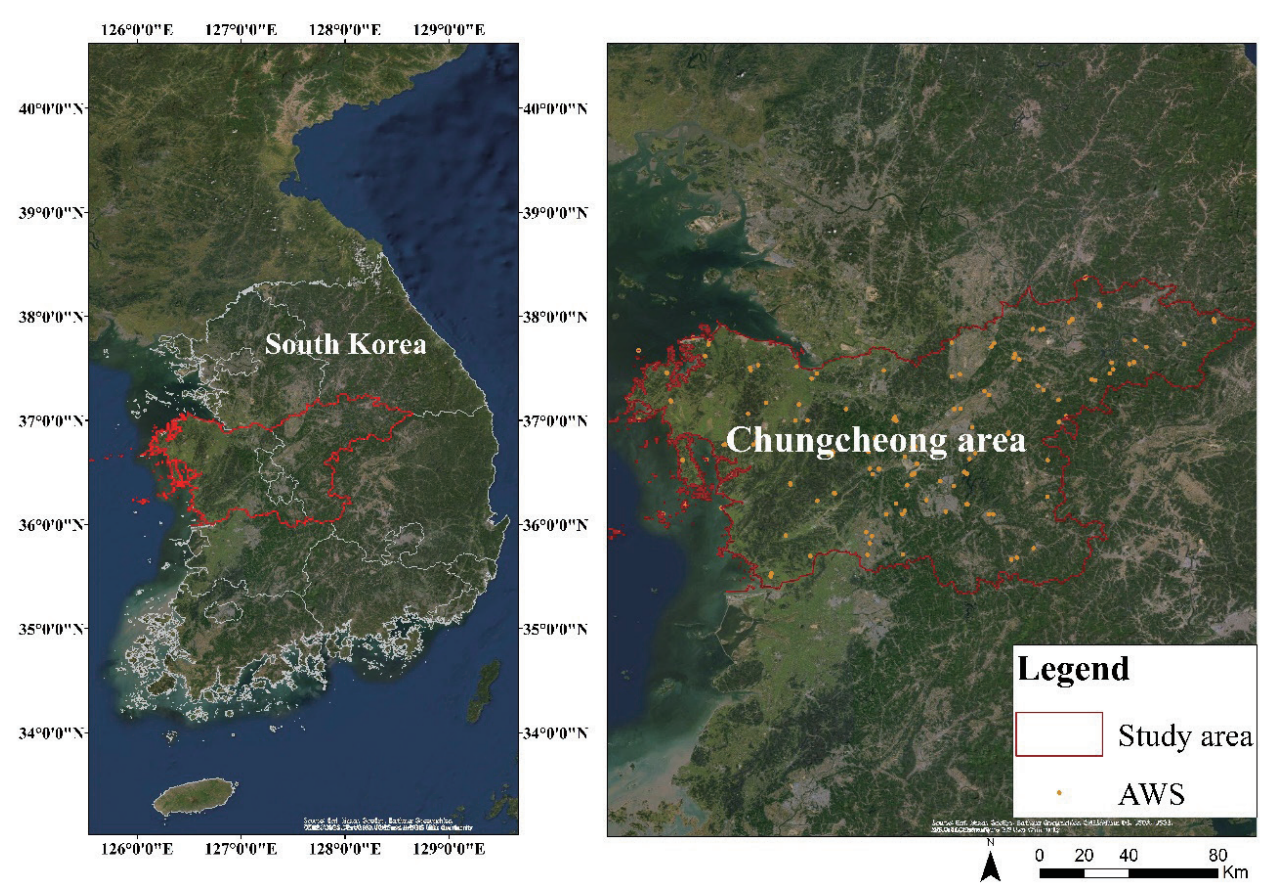

Fig. 1. (Color online) Study area. 
with a resolution of $30 \mathrm{~m} \times 30 \mathrm{~m}$ using Esri ArcGIS 10.8 software. The rainfall variables were selected in consideration of the information on the timing of landslides. No significant changes in the topographic variables were observed over time, and data from a specific period of time were used.

It is necessary to evaluate the predictive ability of landslide control factors to obtain accurate LS modeling. The pre-existing strong correlations between environmental variables in the landslide model adversely affect model performance due to multicollinearity. ${ }^{(21,22)}$ Therefore, in this study, environmental variables were selected using Spearman's rank correlation coefficient, which is an efficient tool for representing the negative or positive correlations between factors. To evaluate LS, nine spatial distribution models were selected from the representative models used in previous studies. The nine spatial distribution models were driven using Biomod2, a statistical package in R script, and the nine models were synthesized by applying the ensemble technique.

The LSAs inside the cultural heritage sites were analyzed using overlapping LS maps and the locations of cultural properties. To identify cultural heritage sites with high LS, cultural properties were classified into 57 types by referring to dictionary definitions then reclassified into seven types according to the classification criteria of the Cultural Heritage Administration. The ratio of LSAs with the seven types of cultural heritage was identified, and those that needed urgent measures to protect them against landslides were identified.

\subsection{Landslide occurrence points}

The points of landslide occurrence in the target years are shown in Fig. 2. The total number of landslides that occurred in the four target years was 273 , most of which were caused by torrential rain and typhoons between June and September. There were 65 landslides in 2011, 43 in 2012, 108 in 2017, and 57 in 2018.

Landslide occurrence point data were collected from Korea Forest Service. The landslide occurrence point data were constructed in two ways. First, data are collected through field investigations by local government officials, which are conducted immediately after a landslide occurs. However, as it is impossible to conduct field investigations in all landslide areas, investigations are primarily conducted in areas where damage to humans and property has occurred. Second, government agencies use satellite image data every year to estimate the locations of landslides and produce a database. A reliable database of landslide occurrences has been established through these two methods. In the data construction method, landslide sites are investigated as close as possible to the trigger point where the landslide started. ${ }^{(23)}$

\subsection{Environmental variables}

The environmental variables used in this study were those identified to be closely related to landslides in previous studies (Table 1). We initially selected 19 environmental variables related to rainfall, topography, land use, and vegetation. Rainfall factors included annual average 


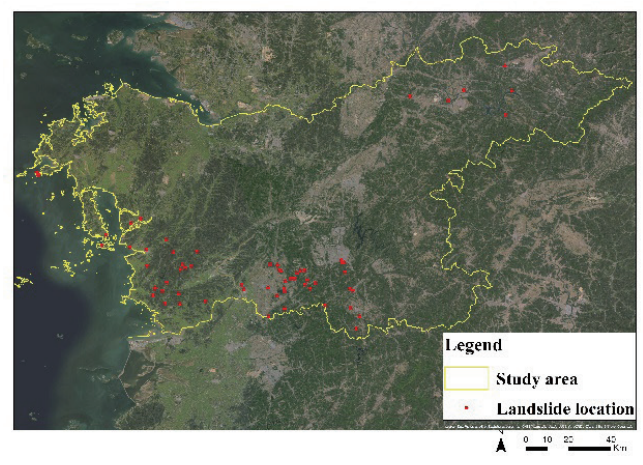

(a)

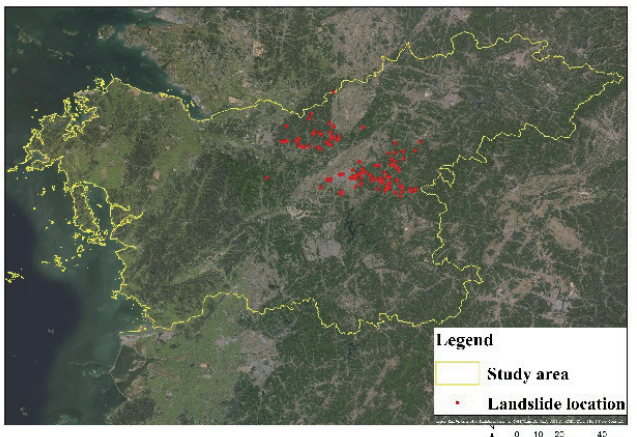

(c)

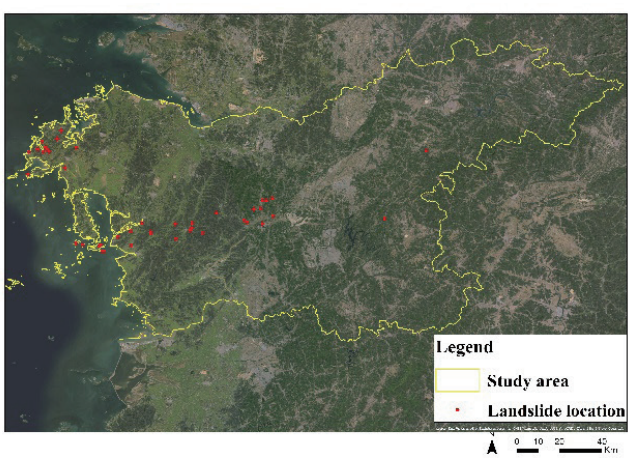

(b)

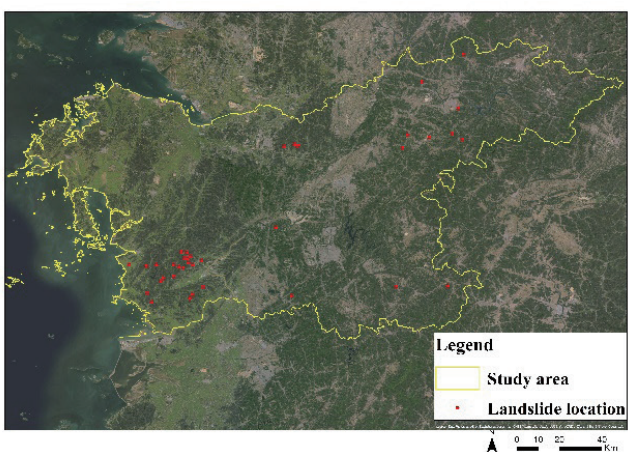

(d)

Fig. 2. (Color online) Landslide points for the four target years. (a) 2011, (b) 2012, (c) 2017, and (d) 2018.

rainfall (TR), days with rainfall of more than $150 \mathrm{~mm}$ (OV150), days with rainfall of more than $80 \mathrm{~mm}$ (OV80), daily maximum (DM) rainfall, and hourly maximum (HM) rainfall.

Topographic factors included elevation, slope, curvature, profile curvature, plane curvature, aspect, stream power index (SPI), topographic wetness index (TWI), and soil depth. The normalized difference vegetation index (NDVI) was selected as the vegetation factor. Land use factors included distance to the nearest road (Road), distance to the nearest river (River), bedrock type (Bedrock), and land use type. ${ }^{(24-27)}$

Among the topographic factors, slope, elevation, profile curvature, plane curvature, aspect, SPI, and TWI were derived from digital elevation model (DEM) data with $30 \mathrm{~m} \times 30 \mathrm{~m}$ resolution provided by the National Geographic Information Service. Soil depth was obtained from the GIS database provided by the National Water Resources Management Comprehensive System. The rainfall factors were subjected to GIS interpolation to create data for the Automatic Synaptic Observation System (ASOS) and Automatic Weather System (AWS) through the Meteorological Administration. The nearest AWS station was used to collect accurate rainfall data (Fig. 1). NDVI was obtained using data from the United States Geological Survey. The distance to the nearest road and the distance to the nearest river were identified using data from the National Geographic Information Service, and the bedrock type was obtained using data provided by the Ministry of Environment. 
Table 1

List of environmental variables. The 19 environmental variables initially used for LSA analysis were collected in consideration of the characteristics of the locations of cultural heritage sites.

\begin{tabular}{|c|c|c|c|c|c|}
\hline Class & Variable & Abbreviation & Type & References & Data references \\
\hline \multirow{5}{*}{ Rainfall } & Annual average rainfall & TR & Continuous & $13,28,29$ & \multirow{5}{*}{$\begin{array}{c}\text { Korea } \\
\text { Meteorological } \\
\text { Administration } \\
(2011,2012,2017, \\
2018)\end{array}$} \\
\hline & $\begin{array}{l}\text { Days with more than } \\
150 \mathrm{~mm} \text { rainfall }\end{array}$ & OV150 & Continuous & $30-32$ & \\
\hline & $\begin{array}{l}\text { Days with more than } \\
80 \mathrm{~mm} \text { rainfall }\end{array}$ & OV80 & Continuous & 30,31 & \\
\hline & Daily maximum rainfall & DM & Continuous & 30,31 & \\
\hline & $\begin{array}{l}\text { Hourly maximum } \\
\text { rainfall }\end{array}$ & $\mathrm{HM}$ & Continuous & 33,34 & \\
\hline \multirow{9}{*}{ Topography } & Elevation & Elevation & Continuous & $13,24,26,28,35-38$ & \multirow{8}{*}{$\begin{array}{c}\text { National } \\
\text { Geographic } \\
\text { Information } \\
\text { Institute (2012) }\end{array}$} \\
\hline & Slope $\left(^{\circ}\right)$ & Slope & Continuous & $2,13,24,26,28,29,35-39$ & \\
\hline & Curvature & Curvature & Continuous & $13,28,35,37$ & \\
\hline & Profile curvature & $\begin{array}{c}\text { Profile } \\
\text { curvature }\end{array}$ & Continuous & $13,28,35-38$ & \\
\hline & Plane curvature & Plane curvature & Continuous & $8,13,28,29,35,36,38$ & \\
\hline & Aspect & Aspect & Continuous & $2,13,24,26,28,29,35-39$ & \\
\hline & Stream power index & SPI & Continuous & $13,26,29,39$ & \\
\hline & $\begin{array}{c}\text { Topographic } \\
\text { wetness index }\end{array}$ & TWI & Continuous & $13,26,28,29,35,36,38,39$ & \\
\hline & Soil depth & Soil depth & Continuous & $0-43$ & WAMIS (2008) \\
\hline Vegetation & $\begin{array}{l}\text { Normalized difference } \\
\text { vegetation index }\end{array}$ & NDVI & Continuous & $13,29,44$ & $\begin{array}{l}\text { United States } \\
\text { Geological } \\
\text { Survey (2018) }\end{array}$ \\
\hline \multirow{4}{*}{ Land use } & $\begin{array}{c}\text { Distance to } \\
\text { nearest road (m) }\end{array}$ & Road & Continuous & $13,28,29,35,36,39$ & \multirow{2}{*}{$\begin{array}{c}\text { National } \\
\text { Geographic } \\
\text { Information } \\
\text { Institute (2017) }\end{array}$} \\
\hline & $\begin{array}{c}\text { Distance to } \\
\text { nearest river (m) }\end{array}$ & River & Continuous & $13,28,29,35,36,39$ & \\
\hline & $\begin{array}{l}\text { Bedrock type } \\
\text { (three types) }\end{array}$ & Bedrock & Categorical & $13,24,28,29,35,36,39$ & \multirow{2}{*}{$\begin{array}{l}\text { Ministry of } \\
\text { Environment } \\
\quad(2010)\end{array}$} \\
\hline & Land use & Land use & Categorical & $13,24,28,29,35,37$ & \\
\hline
\end{tabular}

The rainfall factors are major factors causing landslides because they can affect the shear strength of a slope. Elevation directly affects various environmental conditions, that is, the structure of the vegetation and the climate. Slope affects hydrological conditions, so it indirectly affects landslides. Aspect determines the degree of solar radiation, which can affect soil moisture and slope stability. Plane curvature affects the convergence and dispersion of flows. SPI measures surface runoff erosion capacity and TWI predicts areas sensitive to saturated soil surfaces. The load may depend on the soil depth, which may affect the occurrence of landslides.

The NDVI indicates vegetation conditions and groundwater content, which can affect landslide occurrence. The shorter the distance from the nearest river, the more likely a slope will be damaged by a landslide because the river flow can erode the material and move away from its original position. In areas adjacent to roads, road construction reduces ground stability. There are various types of bedrock in the region, and each type has different characteristics. Some bedrock types are more susceptible to landslides. We reflected information on bedrock through geological maps. 


\subsection{Spatial distribution models}

In this study, representative spatial distribution models used in landslide analysis were run and synthesized into ensemble models to analyze the LSAs. The types of spatial distribution models available are statistical and machine-learning-based; although their reliability depends on the input variables, the machine-learning-based models have been found to have slightly higher reliability. ${ }^{(30)}$ Accordingly, nine spatial distribution models often used in the study of landslides were used in this study (Table 2). The reliability of each model was evaluated by receiver operating characteristic (ROC) analysis of its results and the area under the curve (AUC) value. Additionally, the contributions of each variable applied to the models were calculated, and the relationship between each variable and the landslide site was determined by this calculation. The final LS map was produced by the weighted mean of probabilities (PMW) method as the ensemble method, which had the highest AUC value among the five ensemble models considered in this study (Table 3). ${ }^{(13)}$

Table 2

Spatial distribution models utilized in this study. Nine statistical or machine-learning-based models were used, and the model results were synthesized through the ensemble methods.

\begin{tabular}{lcc}
\hline Abbreviation & Model & Category \\
\hline GLM & Generalized linear model & Statistical model \\
\hline GAM & Generalized additive model & Statistical model \\
\hline GBM & $\begin{array}{c}\text { Generalized boosting model } \\
\text { (usually called boosted regression trees) }\end{array}$ & Machine-learning-based model \\
\hline ANN & Artificial neural network & Machine-learning-based model \\
\hline SRE & Surface range envelope & Machine-learning-based model \\
\hline FDA & Flexible discriminant analysis & Machine-learning-based model \\
\hline MDA & Mixture discriminant analysis & Machine-learning-based model \\
\hline RF & Random forest & Machine-learning-based model \\
\hline MAXENT & Maximum entropy & Machine-learning-based model \\
\hline
\end{tabular}

Table 3

Ensemble methods used to integrate the results of spatial distribution models. In this study, the results of the ensemble model with the highest reliability were utilized.

\begin{tabular}{|c|c|}
\hline Abbreviation & Description \\
\hline PM & Mean of probabilities. This model calculates the mean of probabilities for the selected models. \\
\hline PCI & $\begin{array}{l}\text { Confidence interval. This model is the confidence interval for the probability of the mean and is a } \\
\text { good complement to the PM model. }\end{array}$ \\
\hline PME & $\begin{array}{l}\text { Median of probabilities. This model is the same as the probability of the median for the selected } \\
\text { models. The median is better than the mean for avoiding the impacts of outliers. }\end{array}$ \\
\hline CA & $\begin{array}{l}\text { Model committee averaging. This model first transforms the probabilities of selected models into } \\
\text { binary values by using the cutoff value of each model. After transformation, the model calculates } \\
\text { the average of the binary values. }\end{array}$ \\
\hline PMW & $\begin{array}{l}\text { Weighted mean of probabilities. This model calculates the relative importance of the weights } \\
\text { by using the proportion of evaluation scores. Therefore, the results of "good" models are } \\
\text { discriminated from those of "bad" models. }\end{array}$ \\
\hline
\end{tabular}


Among the nine spatial distribution models, the generalized linear model (GLM) is a generalization of multiple regression models, which employs response variables with a normal distribution using a connection function, that is, response distributions. The generalized additive model (GAM) is a powerful methodology for detecting and explaining nonlinear response functions. The results obtained with the GAM can be used to build a parametric model. The generalized boosting model (GBM) does not apply the same probability to environmental variables, but is similar to a weighted variable that applies a higher selection probability for more important variables. An artificial neural network (ANN) is a two-step classification or regression model. The hidden layer of an ANN consists of features that are a linear combination of input variables. The output variable is a weighted combination of the hidden layers. The surface range envelope (SRE) is a boxcar or parallel pipe classifier using bioclimatic variables (BIOCLIM). The SRE evaluates the potential distribution of dependent variables using multidimensional environmental spaces limited by the values of all dependent variables. Flexible discriminant analysis (FDA) first aligns variables with the multivariate adaptive regression splines (MARS) model and then performs dimension reduction before attempting classification. Mixture discriminant analysis (MDA) is a type of linear analysis that models the multivariate density of variables by mixing multivariate normal distributions. Random forest (RF) is a bootstrap aggregation method that creates relevant trees and averages them, where many trees consist of subsets of input data. In addition, each division of the tree model consists of an arbitrary subset of input variables. Maximum entropy (MAXENT) is based on statistical mechanics and information theory, and the best approximation to an unknown distribution can be analyzed using this method (Table 2).

\section{Results}

\subsection{Model evaluation}

Of the 19 initially selected environmental variables, 14 variables were reflected in the final LS model. In consideration of multicollinearity, variables having a high correlation (0.6) with other environmental variables were excluded from the final LS model. ${ }^{(22,24,45)}$ As a result of Spearman correlation analysis on the 19 environmental variables, five variables (OV80, DM, HM, curvature, and land use) with high correlations were excluded.

The model reliability and the contribution of each variable in each target year were derived from modeling. As the result of the reliability evaluation of the ensemble model, the reliability values decreased in the order $2012>2017>2018>2011$, although all four models had high reliability. The 2011 model showed an AUC value of 0.973 and the contributions of OV150 and TR were high. The 2012 model showed an AUC value of 0.996 with high contributions of TR, elevation, and bedrock. The 2017 model showed an AUC value of 0.993 and the contributions of TR, elevation, and OV150 were high. The 2018 model showed an AUC value of 0.987 with high contributions of OV150 and elevation (Table 4). 
Table 4

Model reliability and variable contribution by target year. The ranking of the contribution of variables differed with the year.

\begin{tabular}{|c|c|c|c|c|c|c|c|c|}
\hline \multirow{3}{*}{$\begin{array}{l}\text { Target year } \\
\text { AUC value }\end{array}$} & \multicolumn{2}{|c|}{2011} & \multicolumn{2}{|c|}{2012} & \multicolumn{2}{|c|}{2017} & \multicolumn{2}{|c|}{2018} \\
\hline & \multicolumn{2}{|c|}{0.973} & \multicolumn{2}{|c|}{0.996} & \multicolumn{2}{|c|}{0.993} & \multicolumn{2}{|c|}{0.987} \\
\hline & Variable & $\begin{array}{c}\text { Percent } \\
\text { contribution } \\
(\%)\end{array}$ & Variable & $\begin{array}{c}\text { Percent } \\
\text { contribution } \\
(\%)\end{array}$ & Variable & $\begin{array}{c}\text { Percent } \\
\text { contribution } \\
(\%)\end{array}$ & Variable & $\begin{array}{c}\text { Percent } \\
\text { contribution } \\
(\%)\end{array}$ \\
\hline \multirow{14}{*}{$\begin{array}{l}\text { Variables } \\
\text { and } \\
\text { contribution }\end{array}$} & OV150 & 39.0 & TR & 36.5 & TR & 60.7 & OV150 & 46.6 \\
\hline & TR & 32.6 & Elevation & 26.2 & Elevation & 17.8 & Elevation & 18.1 \\
\hline & Elevation & 14.0 & Bedrock & 22.7 & OV150 & 13.8 & Bedrock & 12.0 \\
\hline & Road & 12.7 & River & 17.4 & River & 7.4 & TR & 10.7 \\
\hline & Bedrock & 8.9 & Road & 11.4 & Bedrock & 6.8 & Slope & 9.4 \\
\hline & River & 6.3 & Slope & 9.0 & SPI & 6.2 & Road & 7.8 \\
\hline & Aspect & 5.7 & $\begin{array}{c}\text { Profile } \\
\text { curvature }\end{array}$ & 8.5 & Aspect & 5.5 & River & 7.8 \\
\hline & SPI & 5.1 & NDVI & 7.0 & Road & 5.3 & SPI & 7.0 \\
\hline & Soil depth & 4.9 & Aspect & 6.8 & Slope & 4.8 & Aspect & 6.2 \\
\hline & NDVI & 4.6 & OV150 & 6.7 & $\begin{array}{c}\text { Plane } \\
\text { curvature }\end{array}$ & 2.0 & $\begin{array}{c}\text { Profile } \\
\text { curvature }\end{array}$ & 5.5 \\
\hline & Slope & 4.3 & $\begin{array}{c}\text { Plane } \\
\text { curvature }\end{array}$ & 6.3 & Soil depth & 1.3 & Soil depth & 4.5 \\
\hline & TWI & 3.6 & TWI & 5.4 & NDVI & 1.3 & TWI & 4.1 \\
\hline & $\begin{array}{c}\text { Plane } \\
\text { curvature }\end{array}$ & 3.3 & Soil depth & 5.3 & TWI & 1.2 & $\begin{array}{c}\text { Plane } \\
\text { curvature }\end{array}$ & 2.5 \\
\hline & $\begin{array}{c}\text { Profile } \\
\text { curvature }\end{array}$ & 2.7 & SPI & 4.4 & $\begin{array}{c}\text { Profile } \\
\text { curvature }\end{array}$ & 0.9 & NDVI & 2.2 \\
\hline
\end{tabular}

\subsection{LSA}

A map was derived to identify the risk of landslides in cultural heritage sites in the Chungcheong region through the analysis of the LSAs (Fig. 3). The distribution of landslide hazard areas depends on the rainfall pattern, which differed with the year. Since the north of the Chungcheong region is considered to have high LS, it is necessary to manage this risk. In 2011, the LSAs were mainly distributed in the southern part of the study area. In 2017, the LSAs were distributed over a smaller area than in the other years. In 2018, the LSAs were concentrated in the southern and southwestern parts, with some LSAs also distributed in the central and northern parts.

\subsection{LS of cultural heritage sites}

By analyzing the number of cultural heritage sites in LSAs by overlapping the locations of LS maps and state-designated cultural heritage sites, it was found that 200 sites were located in LSAs in 2011, 268 in 2012, 48 in 2017, and 102 in 2018 (Table 5). These cultural heritage sites are likely to experience large-scale damage due to landslides, especially if the entire area of the site belongs to the LSA. There were at least 48 cultural heritage sites in LSAs in the four years, and the number tended to vary greatly with the size of the LSAs. 


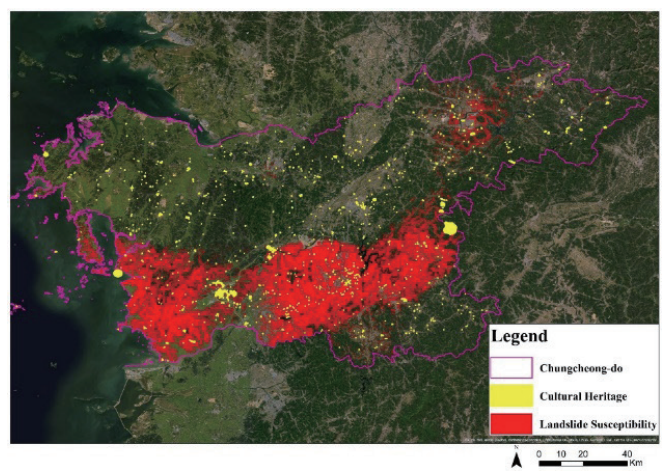

(a)

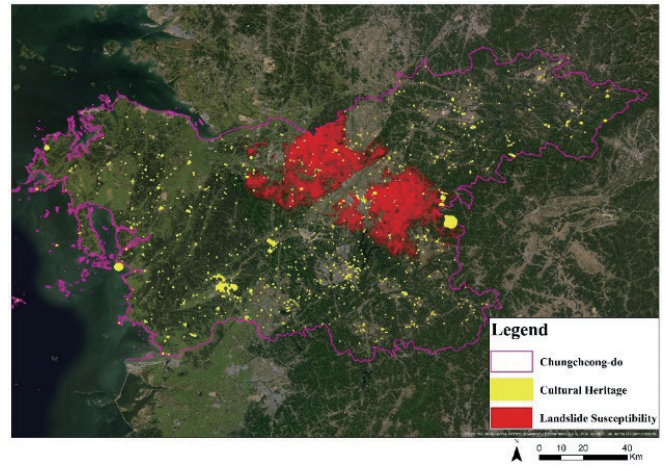

(c)

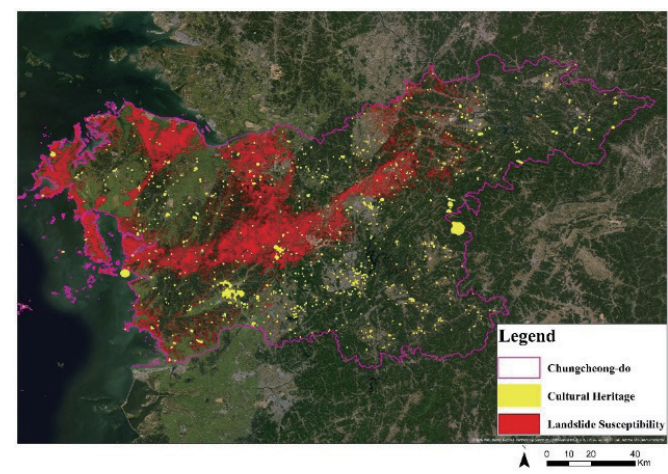

(b)

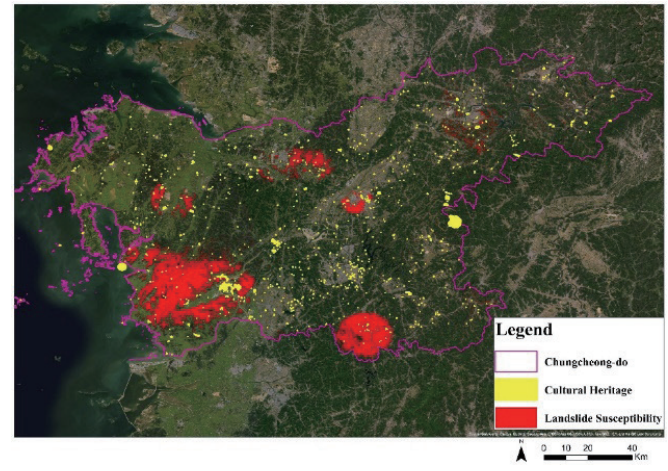

(d)

Fig. 3. (Color online) LSAs of each target year. Areas marked in red have high LS and areas in yellow indicate the locations of cultural heritage sites. (a) 2011, (b) 2012, (c) 2017, and (d) 2018.

Table 5

Number of cultural heritage sites completely or partly located in LSAs.

\begin{tabular}{lcc}
\hline \multirow{2}{*}{ Year } & \multicolumn{2}{c}{ Number of cultural heritage sites } \\
\cline { 2 - 3 } & Completely lying in LSA & Partially lying in LSA \\
\hline 2011 & 200 & 350 \\
\hline 2012 & 268 & 496 \\
\hline 2017 & 48 & 94 \\
\hline 2018 & 102 & 222 \\
\hline
\end{tabular}

The number of cultural heritage sites in LSAs increased significantly from 350 in 2011 to 496 in 2012, decreased to 94 in 2017, and finally increased to 222 in 2018. Even if only part of a cultural heritage site belongs to an LSA, it is highly likely to be directly or indirectly damaged by landslides, making the actual number of cultural heritage sites exposed to landslide damage quite large.

The number of cultural heritage sites belonging to LSAs changed with the target year. In contrast to 2011, when LSAs were concentrated in the southern part of the target region, LSAs were concentrated in the central and northern parts of the target region in 2017, and fewer cultural heritage sites were included in the LSAs (Fig. 3). Although the distribution of cultural heritage sites in the target region is not concentrated in a specific area, it has been confirmed that there are many cultural heritage sites located in areas susceptible to landslides. 


\section{Discussion}

Regarding the types of heritage sites, the total number of different cultural heritage sites located in LSAs in the four target years is in the order religion $>$ history $>$ traditional buildings $>$ tombs $>$ education $>$ landscapes $>$ irrigation facilities (Fig. 4, Table 6). In addition, the number of cultural heritage sites by type located in LSAs as a percentage of the total number of each type of cultural heritage decreased in the order landscape $>$ tombs $>$ religion $>$ history $>$ education $>$ traditional buildings $>$ irrigation facilities (Fig. 5). The cultural heritage types in this study were classified by referring to the criteria of the Cultural Heritage Administration.

In the future, the possibility of landslides is expected to increase owing to the increase in the frequency of torrential rain caused by climate change. As a result, more landslide damage to cultural heritage sites is expected, and efforts should be made in advance to prevent this. As the current policy of the Cultural Heritage Administration, disaster response manuals for protecting cultural heritage are distributed, in which measures are provided to respond to earthquakes, fires, and forest fires. However, these manuals focus only on responses to disasters and recovery from the damage; there is no explanation on how to prevent specific types of disaster such as landslides. Therefore, it is necessary to present specific guidelines for preventing landslide damage to cultural heritage sites.

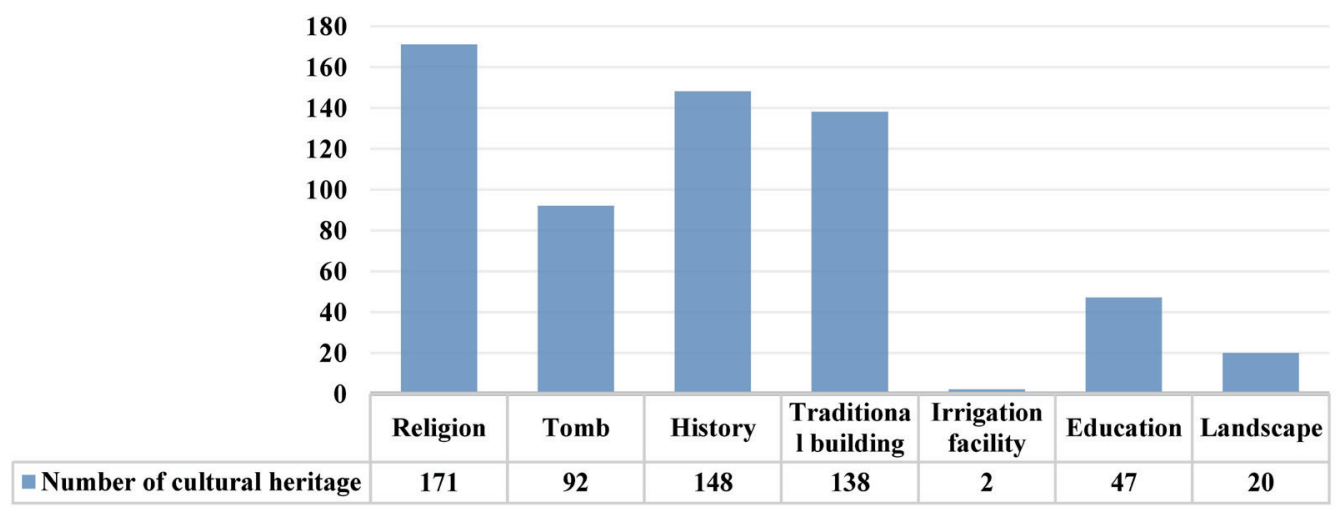

Fig. 4. (Color online) Total numbers of cultural heritage sites located in areas assessed as LSAs in the four years. Sites associated with religion, history, and traditional buildings were the most susceptible types.

Table 6

Numbers and percentages of cultural heritage sites by type in LSAs by target year.

\begin{tabular}{llccccccc}
\hline \multirow{2}{*}{ Year } & Class & Religion & Tombs & History & $\begin{array}{c}\text { Traditional } \\
\text { buildings }\end{array}$ & $\begin{array}{c}\text { Irrigation } \\
\text { facilities }\end{array}$ & Education & Landscapes \\
\hline \multirow{2}{*}{2011} & Number & 55 & 36 & 35 & 54 & 0 & 17 & 3 \\
\cline { 2 - 9 } 2012 & Percentage & 19.5 & 24.5 & 15.3 & 18.4 & 0.0 & 17.7 & 5.6 \\
\cline { 2 - 9 } & Number & 79 & 26 & 70 & 56 & 2 & 22 & 13 \\
\hline \multirow{2}{*}{2017} & Percentage & 28.0 & 17.7 & 30.6 & 19.1 & 25.0 & 22.9 & 24.1 \\
\cline { 2 - 9 } & Number & 15 & 15 & 12 & 4 & 0 & 2 & 0 \\
\hline \multirow{2}{*}{2018} & Percentage & 5.3 & 10.2 & 5.2 & 1.4 & 0.0 & 2.1 & 0.0 \\
\cline { 2 - 9 } & Pumber & 22 & 15 & 31 & 24 & 0 & 6 & 4 \\
\hline
\end{tabular}




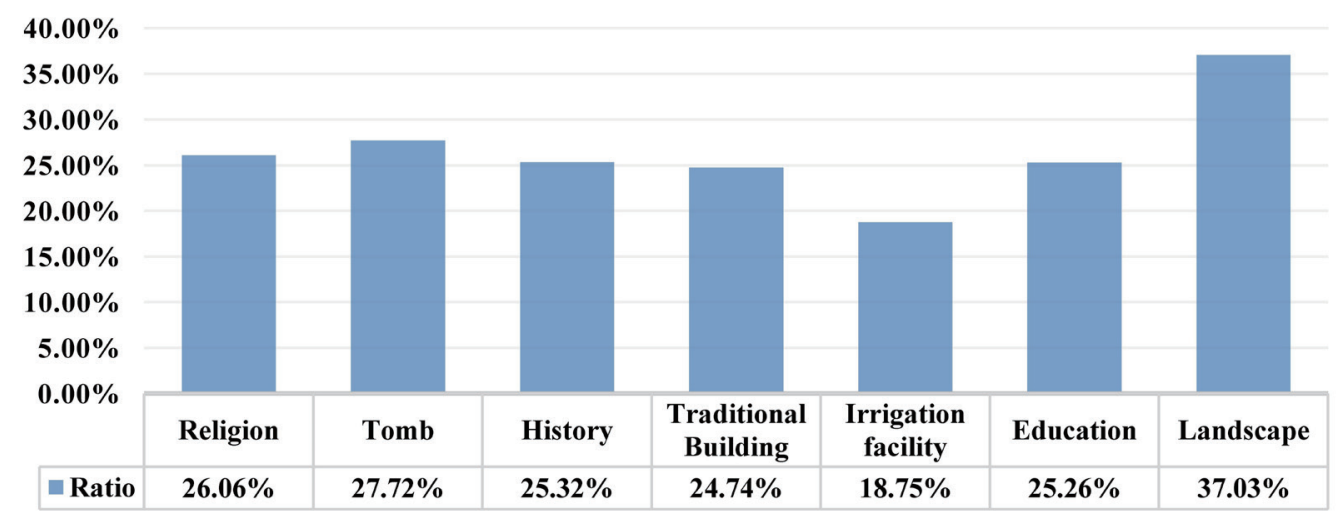

Fig. 5. (Color online) Numbers of cultural heritage sites located in areas assessed as LSAs in the four years by type as percentages of the total number of each type of cultural heritage site.

The concept of the LSA derived from this study is helpful in understanding the priorities for preventing landslides in cultural heritage sites. From the information of cultural heritage sites located in LSAs, it is necessary to identify sites expected to be severely damaged by landslides and to prepare preventive measures. We are unable to evaluate the LS in more detail for individual cultural heritage sites in this study because there are too many cultural heritage sites to deal with. Thus, we propose a method of identifying the priorities for the seven types of cultural heritage site. There are three pieces of information that should be considered as a priority: first, whether the cultural heritage types are included in an LSA in all four target years, second, whether the cultural heritage type is often located in LSAs, and third, whether the proportion of cultural heritages sites belonging to LSAs is high while also considering the total number of cultural heritage sites in question.

The method of identifying priorities was applied to the results derived in this study. In the first phase, the irrigation facility and the landscape types were excluded, which had not been partly or completely excluded in LSAs in all four years. In the second stage, sites associated with religion, history, and traditional buildings were selected, a large number of which were in LSAs. In the third phase, sites associated with religion, which had the highest proportion among the categories, were selected. Therefore, cultural heritage sites associated with religion are considered to require the most urgent attention to prevent landslide damage. Compared with other types of cultural heritage sites, the religious and cultural heritage sites are more likely to be in mountainous areas, so they have a higher LS than other types of cultural heritage sites. The Cultural Heritage Administration should create a budget to establish preferential damage prevention measures for these types of cultural heritage sites.

LS is an important issue for existing cultural heritage sites, but it also needs to be considered for newly discovered cultural heritage sites on steep slopes. It is necessary to introduce procedures to prevent landslides in areas where they are expected through on-site surveys of newly excavated cultural heritage sites. For areas where LS is considered high, slope stability should be reviewed before excavation, and the possibility of landslides should be reduced by installing drainage and restoring slopes in such areas. The LS analysis results derived from this 
study can be used as useful objective evidence in these processes. To prevent casualties during excavation, it is necessary to set an investigation period when landslides do not occur frequently. The prevention of landslides through the restoration of slopes and the installation of erosion control dams must also be considered.

Future research is required due to some limitations of this study. First, since rainfall is a major cause of landslides, it should be possible to evaluate the LS according to changes in rainfall. However, it was difficult to analyze LSAs through the generalization of rainfall variables in this study because detailed precipitation patterns change significantly every year and the land cover changes over time. Second, it was impossible to perform detailed LS analysis on all cultural properties due to the limitations of topographical data. This limitation can be overcome by using remote sensing data in the future.

\section{Conclusions}

We analyzed LS for cultural heritage sites with historical and cultural value in the Chungcheong region. We derived LSAs for four years and analyzed LS for four years rather than for a specific year to reduce specificity. Furthermore, reliable LS analysis results were obtained using ensembles of nine spatial distribution models. The relationship between LSAs and cultural heritage sites by type was analyzed to determine the priority of the landslide response. Since there has been a lack of research on the relationship between cultural heritage sites and LSAs in terms of the possibility of landslide damage, research on the LS of sites should be carried out in various areas in the future. A detailed evaluation of the actual landslide damage prevention process will be required for the cultural heritage sites that were included in LSAs in all four target years. The approach and results of this study provide basic data and guidelines for disaster response plans to reduce and prevent landslides in the Chungcheong region. Considering future climate change scenarios, it is necessary to conduct research to evaluate LS in the future and to acquire basic data on countermeasures to prevent landslides from damaging cultural heritage in the medium to long term.

\section{Acknowledgments}

This work was conducted with the support of the Korea Environment Industry \& Technology Institute (KEITI) through its Urban Ecological Health Promotion Technology Development Project, and funded by the Korea Ministry of Environment (MOE) (2019002770001).

\section{References}

1 M. Napoli, M. Di, D. Di, G. Bausilio, D. Calcaterra, P. Confuorto, M. Firpo, G. Pepe, and A. Cevasco: Water 13 (2021) 488.

2 H. G. Kim, D. K. Lee, and C. Park: Sustainability 10 (2018). https://doi.org/10.3390/su10051628

3 I.-T. Yang, K.-S. Chun, and J.-H. Park: J. Korean Soc. Geospatial Inf. Syst. 14 (2006) 3.

4 S. Jeon, D. Kim, and W. Choi: Korean Soc. Hazard Mitig. 14 (2014) 139.

5 Y. D. Yang, J.-Y. Kim, J.-K. Kim, J.-Y. Lee, M.-S. Kim, S.-H. Lee, J.-C. Kim, W.-H. Nam, and Y.-S. Yang: Korean J. Quat. Res. 21 (2007) 27. 
6 K. Kim: Greenpostkorea (2017). http://www.greenpostkorea.co.kr

7 G. Cho: Newdaily (2020). http://www.newdaily.co.kr

8 K. R. Poudel, R. Hamal, and N. Paudel: Prithvi Acad. J. 3 (2020) 11.

9 E. Sevgen, S. Kocaman, H. A. Nefeslioglu, and C. Gokceoglu: Sensors 19 (2019) 3940.

10 A. Kornejady, M. Ownegh, and A. Bahremand: CATENA 152 (2017) 144. https://doi.org/10.1016/j. catena.2017.01.010.

11 A. -H. Kerekes, S. L. Poszet, and A. Gal: Rev. Geomorfol. 20 (2018) 130.

12 L. Lombardo, F. Bachofer, M. Cama, and M. Märker: Earth Surf. Process. Landforms 41 (2016) 1776.

13 W. Chen, J. Peng, H. Hong, H. Shahabi, B. Pradhan, J. Liu, A. -X. Zhu, X. Pei, and Z. Duan: Sci. Total Environ. 626 (2018) 1121.

14 A. Novellino, M. Cesarano, P. Cappelletti, D. Di Martire, M. Di Napoli, M. Ramondini, A. Sowter, and D. Calcaterra: CATENA 203 (2021) 105317.

15 M.-J. Lee and J.-S. Won: Resour. Environ. Geol. 37 (2004) 425.

16 M. Kim and J. Lee: J. Korean Soc. Hazard Mitig. 18 (2018) 247.

17 M. Schlögl, G. Richter, M. Avian, T. Thaler, G. Heiss, G. Lenz, and S. Fuchs: Natural Hazards Earth Syst. 19 (2019) 201. https://doi.org/10.5194/nhess-19-201-2019

18 E. R. Sujatha: Environ. Earth Sci. 80 (2021) 447. https://doi.org/10.1007/s12665-021-09747-8

19 M. D. Napoli, D. D. Martire, G. Bausilio, D. Calcaterra, P. Confuorto, M. Firpo, G. Pepe, A. Cevasco: Water 13 (2021) 488. https://doi.org/10.3390/w13040488

20 H. G. Kim, D. K. Lee, C. Park, S. Kil, Y. Son, and J. H. Park: Environ. Earth Sci. 73 (2015) 1385.

21 W. Chen, S. Zhang, R. Li, and H. Shahabi: Sci. Total Environ. 644 (2018) 1006. https://doi.org/10.1016/j. scitotenv.2018.06.389

22 Y. Wu, Y. Ke, Z. Chen, S. Liang, H. Zhao, and H. Hong: CATENA 187 (2020) 104396. https://doi.org/10.1016/J. CATENA.2019.104396

23 H. G. Kim and C. Y. Park: Geomatics Nat. Hazards Risk 12 (2021) 2328. https://doi.org/10.1080/19475705.2021 .1950219

24 F. C. Dai and C. F. Lee: Geomorphology 42 (2002) 213. https://doi.org/10.1016/S0169-555X(01)00087-3

25 S. Lee, J. -H. Ryu, and I.-S. Kim: Landslides 4 (2007) 327.

26 P. Vorpahl, H. Elsenbeer, M. Märker, and B. Schröder: Ecol. Modell. 239 (2012) 27. https://doi.org/10.1016/j. ecolmodel.2011.12.007.

27 Y. Yi, Z. Zhang, W. Zhang, Q. Xu, C. Deng, and Q. Li: Nat. Hazards Earth Syst. Sci. 19 (2019) 1973. https://doi. org/10.5194/nhess-19-1973-2019.

28 K. Taalab, T. Cheng, and Y. Zhang: Big Earth Data 2 (2018) 159. https://doi.org/10.1080/20964471.2018.147239 2.

29 Y. Wang, Z. Fang, and H. Hong: Sci. Total Environ. 666 (2019) 975. https://doi.org/10.1016/j. scitotenv.2019.02.263.

30 H. G. Kim: IDI Urban Res. 14 (2018) 93.

31 H. Tang, J. Wasowski, and C. H. Juang: Eng. Geol. 261 (2019) 105267. https://doi.org/10.1016/j. enggeo.2019.105267.

32 M. Floris and F. Bozzano: Geomorphology 94 (2008) 40.

33 J. Premchitt: Guangxi Univ. J. (Natural Science Edition) 40 (2015) 949.

34 A. S. Dhakal and R. C. Sidle: Hydrol. Process. 18 (2004) 757.

35 W. Chen, X. Xie, J. Wang, B. Pradhan, H. Hong, D. T. Bui, Z. Duan, and J. Ma: CATENA 151 (2017) 147. https://doi.org/10.1016/j.catena.2016.11.032.

36 A. Arabameri, B. Pradhan, K. Rezaei, M. Sohrabi, and Z. Kalantari: J. Mt. Sci. 16 (2019) 595. https://doi. org/10.1007/s11629-018-5168-y

37 T. Hamza and T. K. Raghuvanshi: J. King Saud Univ. - Sci. 29 (2017) 151. https://doi.org/10.1016/j. jksus.2016.05.002.

38 J. -C. Kim, S. Lee, H. -S. Jung, and S. Lee: Geocarto Int. 33 (2018) 1000. https://doi.org/10.1080/10106049.2017 .1323964

39 I. Yilmaz: Environ. Earth Sci. 61 (2010) 821. https://doi.org/10.1007/s12665-009-0394-9

40 N. A. Trustrum and R. C. De Rose: Geomorphology 1 (1988) 143. https://doi.org/10.1016/0169-555X(88)90012-8

41 A. M. S. Pradhan and Y. -T. Kim: Environ. Earth Sci. 73 (2015) 5761. https://doi.org/10.1007/s12665-014-3829-x

42 N. Jia, Y. Mitani, M. Xie, and I. Djamaluddin: Comput. Geotech. 45 (2012) 1. https://doi.org/10.1016/j. compgeo.2012.04.007

43 M. S. Kim, Y. Onda, T. Uchida, and J. K. Kim: Geomorphology 271 (2016) 40. https://doi.org/10.1016/j. geomorph.2016.07.031 
44 J. Choi, H.-J. Oh, H.-J. Lee, C. Lee, and S. Lee: Eng. Geol. 124 (2012) 12. https://doi.org/10.1016/j. enggeo.2011.09.011

45 M. L. Gritzner, W. A. Marcus, R. Aspinall, and S. G. Custer: Geomorphology 37 (2001) 149.

\section{About the Authors}

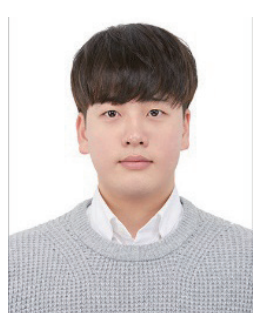

Jun Woo Kim received his B.S. degree from Cheongju University, South Korea, in 2020. Since 2020, he has been pursuing his master's degree at Cheongju University. His research interests are climate change and ecosystem services. (junu7184@gmail.com)

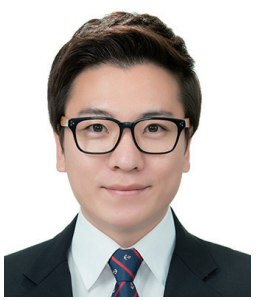

Ho Gul Kim received his B.Sc., M.Sc., and Ph.D. degrees from Seoul National University, Korea, in 2010, 2012, and 2017, respectively. Since 2018, he has been a professor at Cheongju University. His research interests include climate change, ecosystem services, and smart cities. (khgghk87@gmail.com) 